\title{
NOSSO MUNDO GLOBALIZADO ATRAVÉS DO CINEMA À LUZ DE DAVID HARVEY E MILTON SANTOS
}

\author{
Rocio Castro Kustner ${ }^{1}$ \\ Anderson Oliveira Lima² \\ Gabriel Rosa da Conceição Silva ${ }^{3}$ \\ Taíze Ferreira Santos ${ }^{4}$
}

Resumo: O presente trabalho tem como objetivo trazer uma reflexão sobre aspectos sócio-espaciais da globalização contemporânea à luz dos "Espaços de esperança" de David Harvey (2004) e "Por uma outra globalização", de Milton Santos (2000), dialogando com quatro filmes que foram debatidos em aula no ensino da disciplina "Aspectos Sociológicos da Análise Geográfica" do Curso de Licenciatura em Geografia. Os filmes são: "Um Filme falado", "Babel", "Ensaio sobre a cegueira" e "Era o Hotel Cambridge"; entendendo o cinema como uma importante ferramenta audiovisual para a compreensão do espaço geográfico como uma construção histórico-social; e a globalização como reestruturação geográfica do capitalismo (HARVEY, 2004) que apresenta como fábula o que é vivido como perverso, mas poderia ser outra globalização (SANTOS, 2000). O trabalho termina reflexivamente trazendo um breve balanço das perspectivas da globalização na pandemia do COVID-19.

Palavras-chave: Civilização Ocidental, Globalização, Unicidade da técnica.

\section{OUR GLOBALIZED WORLD THROUGH THE CINEMA TALKING WITH DAVID HARVEY AND MILTON SANTOS}

Abstract: This paper aims to bring a reflection about social-spacial aspects of contemporanean globalization through "Spaces of hope", by David Harvey, and "Toward another globalitation", by Milton Santos, in dialogue with four films debated in Geography class during the teaching of "Sociologist Aspects on the Geographic Analysis": "A talking picture", "Babel", "Blindness" and "The Cambridge squatter"; understanding cinema as an important audiovisual tool for the comprehension of geographic space as a social-historic construction, and the globalitation as geographic reestruturation of capitalism (Harvey) that shows as fable what is lived as perversion, but it could be "another globalitation" (Santos). The paper ends up

\footnotetext{
${ }^{1}$ Professora da Universidade do Estado da Bahia - UNEB (Campus V - São Antônio de Jesus). Email: rkustner@uneb.br ${ }^{2}$ Graduando no curso de Geografia da Universidade do Estado da Bahia/UNEB (Campus V - São Antônio de Jesus). Email: anderson.bitolima01@gmail.com

${ }^{3}$ Graduando no curso de Geografia da Universidade do Estado da Bahia/UNEB (Campus V - São Antônio de Jesus). Email: gabriel.ceavb@gmail.com

${ }^{4}$ Graduando no curso de Geografia da Universidade do Estado da Bahia/UNEB (Campus V - São Antônio de Jesus). Email: ferreirataize@outlook.com
} 
bringing a brief balance and perperstives about globalitation in the pandemia of COVID-19.

Keywords: Ocidental civilitation, Globalitation, Technique Unicity.

\section{INTRODUÇÃO}

Considerando o cinema como uma importante ferramenta audiovisual para analisar a produção do espaço geográfico na sua dinâmica social, uma seleção de filmes foi escolhida para o ensino da disciplina "Aspectos Sociológicos da Análise Geográfica" do Curso de Licenciatura em Geografia com o intuito de auxiliar: a) na compreensão do espaço geográfico como uma construção histórico-social e palco das transformações derivadas da ação social que, por sua vez, cria a cultura e as relações de poder nela implícitas; b) na análise da construção dos territórios denominados estados-nações e das novas territorialidades com suas novas relações e os conflitos locais derivados dos processos de globalização.

O intuito da disciplina, também, é de refletir sobre as novas alternativas para outro mundo possível, sempre partindo do global dialogando com o local, considerando que grande parte das comunidades locais está inserida no mundo global desde antes que se falasse de globalização. De certa forma, já começou com a ocupação de territórios desde as navegações primeiramente pelo Mediterrâneo, berço da civilização ocidental (como nos convida a refletir "Um Filme Falado"); depois, através dos oceanos com a colonização das Américas, da Índia e da África. Ainda podemos nos remeter mais remotamente à milenar Rota da Seda, que desde a China, atravessando grande parte dos territórios da Eurásia, teve suas contribuições na formação da civilização ocidental, que tem liderado os processos de globalização. Por isso que o entendimento de processos globais como 0 colonialismo, a industrialização e o capitalismo ajuda a analisar de que forma a produção do espaço em nosso mundo local foi marcada pelo seu contexto histórico - isso também seria o "ler o mundo" de Freire, sempre e quando o global nos dê o contexto histórico do local para entender as dimensões significativas da nossa realidade e, assim reciprocamente, nos aproximar do mundo global. Estabelecemos, assim, uma dialética através da qual a leitura do local se retroalimenta do global tanto em quanto o global esteja contido no local, para observar nosso lugar no mundo e como curiosamente o centro do mundo pode ser qualquer lugar.

Falar de globalização, e "por uma outra globalização" em geografia, nos remete a David Harvey (2004) e Milton Santos (2000), que têm sido, junto com outros teóricos, os grandes norteadores da disciplina mencionada e do presente trabalho, que dialoga com quatro dos filmes tratados em sala de aula: "Um Filme Falado", "Babel", "Ensaio sobre a Cegueira" e "Era o Hotel Cambridge" (CAFFÉ, 2016).

Assim, o presente trabalho surge de um diálogo começado na sala de aula, que nos levou a formar um grupo de estudo fortemente consolidado durante a quarentena da Pandemia do coronavírus. A palavra pandemia nos remete à globalização: de origem grega, como a civilização ocidental, e composta por pan = todos e demo = povo - tem levado o mundo todo a encarar situações inéditas que nos estão convidando também a refletir sobre as mazelas da globalização perversa na linha que já sinalizava Santos e Harvey, além de outros cientistas sociais não geógrafos como Giddens, Hall, Castells, Edgar Morin, Souza Santos e tantos outros. 
O mundo confusamente percebido se faz evidente quando políticas públicas que se preocupam com as vítimas da pandemia são vistas como "ameaças comunistas" pela cegueira que Saramago que já deslumbrou em 1995 no seu famoso ensaio. Sobre todos estes assuntos refletidos no grupo trata o presente trabalho, partindo de um histórico das origens da civilização ocidental, que pode ser considerada como o embrião da globalização.

Partindo do pressuposto de que "nosso papel não é falar ao povo sobre a nossa visão do mundo, mas dialogar com ele sobre a sua e a nossa", com "o esforço de propor aos indivíduos dimensões significativas de sua realidade, cuja análise crítica lhes possibilite reconhecer a interação com o mundo" (FREIRE, 1987, p. 41 e 55), a dialogicidade freiriana foi praticada com o uso do cinema como instrumento metodológico.

Foi um 28 de dezembro de 1895 quando os irmãos Lumière realizaram a primeira exibição pública de cinema num café-teatro de variedades em Paris, com um programa de 25 minutos de dez filmes documentando cenas da vida cotidiana como "A saída dos Operários das Usinas Lumière" e "A chegada do trem na Estação", e em questão de meses os filmes se espalharam por várias partes do mundo (SOUZA, 2017). Desde então, o cinema tem cativado o mundo das artes contribuindo para conformar uma sociedade de massa que já começou a se destacar com a explosão do jornal, no século XIX, e se intensificou com o rádio e a televisão como "novas maneiras de estar juntos" (AGNEZ, 2009). Nesse sentido, o cinema pode ser caracterizado também como Santos $(2000$, p. 25) caracteriza a globalização, com sua "unicidade da técnica, convergência dos momentos e aproximação planetária", abrindo uma nova etapa histórica.

$\mathrm{Na}$ era da globalização, as massas navegam nas mídias digitais, que vão esvaziar o cinema como espaço coletivo do mundo visual, um mundo visual submetido à velocidade de propagação da informação, de todo tipo de informação, desde todos os cantos do planeta e de qualquer fonte, até das fakes news (palavra muito globalizada). No mundo da unicidade da técnica da internet, o celular e do WhatsApp, ficou mais difícil captar a atenção dos jovens. O grande desafio é incentivar uma cultura de cinema entendida como ação coletiva de reflexão comum e troca de ideias na construção de um mundo menos confuso, por ser mais compreendido desde o momento em que o cinema é vivido coletivamente e acompanhado de uma reflexão crítica a partir de nossa realidade local e em diálogo com os outros em rodas de conversa características do cineclube.

Como nos fala Oliveira Jr. (2006, p. 29) "a ideia das geografias de cinema é de que somos nós que "colocamos" nas imagens e sons os sentidos que terão nessa interpretação espacializada das obras cinematográficas". Por isso se faz necessária a educação visual, essencial para decifrar a linguagem do cinema, que não tem em si significação predeterminada - as imagens produzem significados, e:

a significação depende essencialmente da relação que se estabelece com outros elementos. Este é um princípio fundamental para a manipulação e compreensão dessa linguagem...Filmar então pode ser visto como um ato de recortar o espaço, de determinado ângulo, em imagens, com uma finalidade expressiva. Por isso, diz-se que filmar é uma atividade de análise. Depois, na composição do filme, as imagens filmadas são colocadas umas após as outras. Essa reunião das imagens, a montagem, é então uma atividade de síntese (BERNARDET, 2017, p. 18). 
Decifrar essa montagem crítica e coletivamente através do exercício analítico e sintético é tarefa do ensino visual, mais ainda no ensino da geografia, que tem uma dimensão visual muito forte se concordamos que ela "é, acima de tudo, conhecimento obtido a partir da observação, que se ordena a partir da reflexão e reinspeção das coisas que se olham" (SAUER, apud FIORANTE; FERREIRA, 2016, p. 219). Segundo outro autor, Thorne (apud FIORANTE; FERREIRA, 2016, p. 228), "o ensino visual é uma habilidade que a Geografia precisa abraçar, pois a interpretação de materiais visuais sempre foi importante no ensino de geografia e é a característica que a torna única".

Além da dimensão visual, a espacial também ocupa um papel central tanto na Geografia quanto no cinema. Como sinalizam Fioravante e Ferreira (2016, p. 229):

o cinema sempre foi, desde suas origens, fascinado pela representação de espaços distintos, estilos de vida e condições sociais e o processo de criação de um filme requer que os estudantes [...] se tornem mais atentos acerca das maneiras através das quais eles próprios compreendem, vivenciam e representam os espaços.

No cinema, igual que no mundo real, os espaços geográficos são o palco onde se desenvolvem as tramas da vida, seja real ou imaginária, criando assim representações do mundo real ou imaginário, e, como nos fala Queiroz (2005, p. 159), "ao assumirmos que há uma dimensão espacial inerente à linguagem cinematográfica [...] estamos partindo do argumento de que a experiência do cinema é uma experiência geográfica" onde os espaços se apresentam em miniatura, condensando e enriquecendo os valores; também, observamos, radicalizando e/ou exagerando os conflitos. Ainda Queiroz (2005) observa o papel protagonista da imagem no mundo contemporâneo colocando a modo de exemplo um fato relevante para compreender os processos de globalização: a produção da imagem do mundo como uma aldeia global, "um grande território sem fronteiras, está cada vez mais presente na vida das pessoas" (QUEIROZ, 2005, p. 164). Veremos como isto seria para Santos (2000) a globalização como fábula.

Os filmes são janelas para o mundo, formas de viajar pela geografia real e/ou imaginária; quando lidos criticamente como textos, como Paulo Freire ensinava a ler o mundo, ajudam a desenvolver uma visão muito interdisciplinar, trazendo noções de tempo (história) e espaço (geografia, física e biologia) na abordagem de toda ação humana (social, cultural e até artística) e de seu uso do espaço, que envolve questões sociais, econômicas e políticas. Assim, em palavras de Oliveira Jr. (2006, p. 32):

As geografias de cinema, frutos de interpretações subjetivas e de pesquisa das imagens e sons fílmicos, buscam desliteralizar as interpretações habituais dadas a estes filmes... por isso terminam sendo uma proposição educativa, além de poética, das obras do cinema.

Mediante a observação atenta e direta desse mundo representado pelo cinema, os estudantes podem desenvolver com capacidade de análise e síntese 0 olhar aguçado e crítico que permita uma interpretação "desliteralizada" das geografias do cinema desde um espaço fechado de um lugar concreto, como pode ser um manicômio ("Ensaio sobre a Cegueira"), um prédio ("Era o Hotel Cambridge"), até espaços abertos que unem vários continentes ("Um Filme Falado" e "Babel"). Mesmo que o cinema tenha sido um de nosso instrumento para a análise 
geográfica dos aspectos sociológicos, mas do que reparar na análise de imagens e sons cinematográficos, no presente trabalho refletimos sobre todos esses espaços geográficos, cinematograficamente representados, no contexto da globalização contemporânea e tirando o máximo proveito para nos aprofundar no conhecimento tanto da sua localização geográfica quanto da sua formação histórica e seu papel geoestratégico nos processos de globalização, num exercício de aproximação ao nosso mundo global para melhor entender nosso lugar no mundo.

\section{A GLOBALIZAÇÃO CONTEMPORÂNEA DE DAVID HARVEY (2004) E PERVERSA DE MILTON SANTOS (2000)}

Em "Espaços de esperança" Harvey (2004) define a globalização como um processo de reestruturação geográfica do capitalismo, em constante transformação do espaço geográfico. De certa forma, esse processo começou a se originar por volta da segunda metade do século $\mathrm{XV}$, quando a internacionalização das trocas mercantis estava em pleno desenvolvimento com as grandes navegações, que por sua vez, tiveram seu início no Mediterrâneo - berço da civilização ocidental. Todavia, para Harvey, podemos falar propriamente de globalização a partir do momento em que os Estados Unidos da América (EUA) perderam a sua hegemonia mundial, isto é, deixaram de ser a liderança econômica que se ergueu após a Segunda Guerra Mundial, com a crise do petróleo e a desregulamentação financeira mundial na década de 1970. Até então, falávamos primeiro de colonialismo europeu e depois de imperialismo ianqui.

O colonialismo se desenvolveu entre meados do século XV e o final do XIX, período em que os europeus exploraram de forma intensiva as riquezas das Américas e da África, na base de atividades de grande impacto geográfico, como o monocultivo e a extração mineral. Para isso, foram construídos engenhos, casas grandes, portos e suas trilhas de acesso, cidades e mais tarde ferrovias para fazer circular a máquina de vapor que abriu passo à Revolução Industrial gestada na Inglaterra, graças a todas estas riquezas extraídas do Novo Continente. E logo depois, demarcação das fronteiras com as guerras da independência para a formação dos estados-nações à imagem do modelo europeu da llustração importada.

Harvey nos lembra como a maioria das fronteiras entre países da Terra foi estabelecida entre 1870 e 1925, ou seja, recentemente. Ainda vários deles só se tornaram de fato independentes depois de 1945, após a Segunda Guerra Mundial. Podemos dizer que estas mudanças geopolíticas, a partir de demarcações claras do espaço, formam parte também de um processo contínuo e inacabado de reestruturação geográfica, como vimos recentemente na dissolução da antiga União Soviética e de lugoslávia, e como ainda vemos em Israel, que, desde sua formação como estado após a Segunda Guerra Mundial, vem disputando território com a Palestina.

O processo de formação dos estados-nações tem como pano de fundo a Revolução Industrial, quando o mercantilismo veiculado pelas grandes navegações foi substituído pela acumulação do capital veiculada pelos motores em torno aos novos espaços geográficos delimitados pelas fábricas, os centros urbanos que vão se construindo ao seu redor e as estradas de ferro e asfalto que tecem as conexões entre os territórios. Desta forma, fomos chegando na "fase superior do capitalismo", descrito por Lenin em 1916 como imperialismo - domínio do capital financeiro, 
quando o acúmulo de capital levou às grandes empresas a depender dos bancos, e estes pela sua vez começaram a especular com os terrenos dos subúrbios operários das cidades industriais, monopolizando a renda da terra, as vias de comunicação e o acesso aos centros urbanos que "se encontram nas mãos de grandes companhias, ligadas a esses mesmos bancos mediante o sistema de participação e de distribuição dos cargos diretivos" (LENIN, 2011, p. 172-173).

Esse novo processo continuou sendo liderado pela Europa, desta vez pelos países mais industrializados - aqueles que melhor souberam lucrar com as riquezas extraídas das colônias - sob a égide dos Estados Unidos, que começam a se destacar desde o final do século XIX, tendo seu ápice após a Segunda Guerra Mundial, quando se erige "guardiã do mundo", e os intercâmbios comerciais passam a ser atrelados a sua moeda nacional, o dólar, no Tratado de Bretton Woods (1949). Mesmo sendo o primeiro acordo internacional de uma ordem monetária entre os países mais industrializados, para Harvey (2004), a globalização propriamente dita se dá a partir do momento em que Estados Unidos deixam de ser a única liderança econômica mundial após a crise do petróleo da década 1970, e entram em cena os outros blocos econômicos que irão conformar a Tríade: Japão, a Comunidade Econômica Europeia (CEE) e o Tratado do Atlântico Norte (NAFTA) - formado pelos Estados Unidos, México e Canadá - mas sempre com os Estados Unidos a frente:

A globalização foi sendo construída em parte por meio de uma ampla variedade de agentes (particularmente governos de nações-Estados) que pensavam localmente e agiam globalmente de uma maneira que em nada diferia da ação dos Estados Unidos como a potência hegemônica que movia as engrenagens do processo como um todo (HARVEY, 2004, p. 100).

Desse modo, houve a mudança de um sistema imperialista que nos seus anos finais era hierarquicamente controlado pelos Estados Unidos, para um sistema mais descentralizado (globalizado) e mais favorável para a difusão do capitalismo, desta vez tendo como protagonismo as grandes corporações: multinacionais ou transnacionais desses grandes blocos econômicos que, como a palavra indica, transpassam as fronteiras nacionais pelas estradas, mares, céus e virtualmente. Para isso, o espaço tem sido dotado de sistemas de transportes mais rápidos, tecnologias informatizadas que facilitam a circulação do capital financeiro e monetário, e de infraestruturas que reduzem as distâncias entre os diferentes lugares da Terra; tudo em função de acelerar o fluxo de mercadorias e de capital para permitir rápidos ajustes de localização da produção e de consumo, o que tem ocasionado sérios impactos (HARVEY, 2004).

$\mathrm{Na}$ globalização contemporânea os diferentes lugares do planeta se interligaram por meio de rodovias, vias férreas, transportes marítimos, aéreos e virtuais, facilitando o deslocamento de pessoas e mercadorias de forma global, com o intuito de tornar possível que as indústrias multinacionais e transnacionais realizem as suas produções de forma também descentralizada e mais lucrativa para isso, escolhendo os países que oferecem mão de obra barata. Com isto, o perfil da população trabalhadora tem também mudado no mundo: as grandes corporações têm empregado mais mulheres a até crianças nos países periféricos, ao mesmo tempo em que um contingente da população destes países emigrou e ainda está emigrando para os Estados Unidos e Europa, a procura de emprego, fato que tem transformado o Mediterrâneo e as fronteiras México-Estados Unidos em espaços de tragédia multitudinária. 
Ainda, iniciamos o ano 2020 com o fenômeno global da pandemia do coronavírus, que se originou na China, mas que em pouco tempo se alastrou por quase todo o globo terrestre, pegando todo o mundo de surpresa e despreparado, principalmente na Europa e nos Estados Unidos. A pandemia está causando uma das maiores crises da história da Organização Mundial da Saúde, desencadeando medo, apreensão, pânico e, sobretudo, mortes que nos lembram ao que Harvey já sinalizava em 2004 e Milton Santo em 2000. É a globalização perversa que, na sua obra "Por uma outra globalização", Milton Santos (2000) reflete como nos faz viver num mundo confuso e confusamente percebido quando é apresentado como fábula o que é perversidade.

Uma das primeiras fábulas que se tornou mito é a ideia de que o mundo é uma aldeia global aproximada espacialmente pela facilidade que os meios de transporte dão para viajar a qualquer distância - a mobilidade internacional se intensificou, como pode ser observado no trânsito no espaço aéreo, mas não deixa de ser facilidade para uma minoria privilegiada que pode viajar. Enquanto que:

$\mathrm{Na}$ verdade, as diferenças locais são aprofundadas. Há uma busca de unificar os serviços dos atores hegemônicos, mas o mundo se torna menos unido, tornando mais distante o sonho de uma cidadania verdadeiramente universal (SANTOS, 2000, p. 120).

A velocidade e a facilidade do trânsito pelos espaços diversos do planeta desse setor minoritário dos privilegiados dão a imagem de uma humanidade desterritorializada, de cidadãos de um mundo sem fronteiras - humanidade desterritorializada e cidadania universal são outros mitos que, segundo Santos (2000, p. 42) a globalização como fábula apresenta, pois mesmo que "as fronteiras mudaram de significado, nunca estiveram tão vivas" e "o exercício da cidadania [...] é ainda um fato que depende da presença e da ação dos estados nacionais" (SANTOS, 2000, p. 42). A realidade que vemos perante qualquer crise são as fronteiras se fechando e os estados se protegendo da "invasão do estrangeiro", com receio do fantasma do terrorismo ou dos imigrantes "roubarem" os empregos dos nacionalistas, dentre outros fatores - caso Brexit, refugiados se afogando no Mediterrâneo, os novos muros de Ceuta e Melila e na fronteira de México com Estados Unidos.

A chegada da era informacional, por meio da cibernética, da informática e da eletrônica, contribuiu para a difusão da globalização como fábula. Através da mídia são transmitidas imagens que iludem as massas populares, com intuito de divulgar apenas situações prazerosas, que estimulam o desejo de se integrar cada vez mais no sistema capitalista desse setor minoritário que viaja sem fronteiras. Na tentativa de alcançar a fábula da globalização, muitas pessoas, para fugir da miséria de seus países de origem migram para os lugares em destaque na mídia, como Estados Unidos para os latino-americanos, Europa para moradores do Oriente Médio e da África, e São Paulo para os nordestinos. Estes mitos formam parte do mundo confusamente percebido que desorienta e, consequentemente, traz insegurança e medo, de tal forma que, nos diz Santos (2000, p.58):

Jamais houve na história um período em que o medo fosse tão generalizado e alcançasse todas as áreas da nossa vida: medo do desemprego, medo da fome, medo da violência, medo do outro. Tal medo se espalha e se aprofunda a partir de uma violência difusa, mas estrutural, típica do nosso tempo. 
O medo parece ter-nos paralisado, nos fazendo tolerar as mais adversas situações. Tempos há que nos habituamos com a violência e o subemprego. Santos (2000) descreve como a globalização se impõe de forma perversa para a maior parte dos trabalhadores e desempregados ameaçados pelos estados-nações, que aprovam políticas públicas diminuindo os direitos trabalhistas conquistados após anos de muitas lutas. Nas palavras de Santos (2000, p.19-20):

De fato, para a maior parte da humanidade a globalização está se impondo como uma fábrica de perversidades. O desemprego crescente torna-se crônico, a pobreza aumenta e as classes médias perdem em qualidade de vida, o salário médio tende a baixar, a fome e o desabrigo se generalizam em todos os continentes, novas enfermidades como a SIDA se instalam e velhas doenças, supostamente extirpadas, fazem seu retorno triunfal.

A pandemia do coronavírus está evidenciando de forma mais globalizada do que nunca o lado perverso dessa globalização liderada primeiramente pelos Estados Unidos e seguida da Tríade, mas que de certa forma teve seu embrião no Mediterrâneo, berço da civilização ocidental, como comentamos e veremos no Filme Falado de Manoel de Oliveira (2004).

\section{DAS NAVEGAÇÕES DO MEDITERRÂNEO AO MUNDO GLOBAL: "UM FILME FALADO" DIALOGANDO COM HARVEY}

Um Filme Falado (DE OLIVEIRA, 2004) começa com uma professora de História e sua filha embarcando em Lisboa, em um cruzeiro pelo Mediterrâneo com paradas em históricas cidades localizadas no Ocidente e no Oriente - Marselha, Nápoles, Atenas, Istambul, Alexandria e Áden - palco desde onde a professora aproveita para contar a sua filha a história de lugares tão transitados desde a época das primeiras navegações sobre as águas do mar que foi berço da Civilização Ocidental. O filme convida a refletir sobre a história da civilização ocidental, tecida através de intensos contatos culturais e constantes confrontos políticos, que eram ocasionados, principalmente, pelas trocas comerciais facilitadas pela localização geográfica de um mar que banha três continentes. Neste convite, faremos uma breve contextualização sócio-histórica dos lugares do Mediterrâneo escolhidos pelo diretor do filme para melhor entender a mensagem que quis transmitir.

A parada do cruzeiro em Marselha é muito simbólica. A marca do império grego "levando a civilização", como fala a historiadora do filme, nas suas navegações pelo Mediterrâneo, projetou esta cidade para o mundo global, desde sua fundação seis séculos antes de Cristo, como principal porto para o tráfego de mercadoria. Bom lembrar agora que, durante a colonização francesa na África e na Ásia e após a abertura do Canal de Suez em 1869, se intensificou o trânsito de mercadoria e passageiros na cidade que, após a primeira Guerra Mundial transformou-se em grande complexo industrial e, a partir de 1960, porto de entrada de grande contingente de emigrantes, na sua maioria do norte da África, na França, e do petróleo na Europa.

Neste ponto, o intuito de Manoel de Oliveira, através do diálogo entre a historiadora e o pescador que nesse porto se encontram, é refletir sobre o mundo que construímos em torno do petróleo e as guerras levantadas por conta dele, ainda na raiz dos conflitos entre o Ocidente e Oriente, e que levarão o filme a um trágico 
destino, sem volta para trás, como lamentou o pescador - "Ocidente no abismo, e com ele todos os lugares por onde espalhou a sua civilização". Vale lembrar que Manoel de Oliveira rodou o filme três anos após a grande tragédia para o Ocidente, o atentado as Torres Gêmeas em Nova York (11 de setembro de 2001), fato que marcou um antes e um depois na história global, obrigando as companhias aéreas, cada vez mais ativas no fluxo internacional de pessoas, a tomar minuciosas medidas de segurança - como a pandemia do coronavírus as têm feito.

Outra parada muito simbólica do cruzeiro no filme foi Istambul, capital da Turquia e a antiga Constantinopla capital do Império Romano do Oriente ou Bizantino, iniciado três séculos depois de Cristo. O Império Bizantino deu fim à Idade Média e sua capital durante esse tempo foi centro de confluência do Ocidente com o Oriente e ponto principal das grandes rotas terrestres e marítimas do comércio com a Ásia (RUNCIMAN, 1961). No Filme Falado, Manoel de Oliveira apresenta como lugar de fusão do Ocidente com o Oriente a obra arquitetônica e de maior poder simbólico da Turquia, que outrora fosse a catedral de Santa Sofia, posteriormente mesquita, depois museu e no ano de 2020 declarada mesquita de novo. Edificada durante o Império Bizantino por Justiniano em 573, foi centro de propagação da cultura bizantina em toda a Europa Oriental e na Rússia, até que os turcos tomaram Constantinopla e a converteram em mesquita em 1453 (RUCIMAN, 1961).

Quando o cruzeiro chega ao Egito, no relato que a historiadora vai fazendo para sua filha tomam protagonismo, além das Pirâmides, dois lugares marcantes na história da humanidade: a biblioteca de Alexandria e o Canal de Suez - lugares sobre os que recordaremos sua história para melhor entender seu significado no filme. Alexandria, no delta do Nilo, é uma cidade de localização também estratégica por estar situada na convergência entre o Oriente e o Ocidente, entre o Norte e o Sul. Tomou seu nome do imperador grego Alexandre o Grande, que três séculos antes de Cristo arrebatou o Egito das mãos dos persas, sendo muito bem acolhido pelos egípcios acostumados à convivência com os gregos - naquela época a cidade estava cheia de gregos, e bom lembrar que muitos dos filósofos gregos, como Pitágoras e Hipócrates, pai da medicina, se nutriram do conhecimento dos egípcios. Alexandria naquela época era outra Nova York, com bairros judeus e de outras partes do mundo (ALVES, 2004).

De outras partes do mundo chegavam a Alexandria barcos com todo tipo de mercadoria, dentre elas escritos em milhares de rolos de papiro, os precursores dos livros - "o primeiro livro da história nasceu quando as palavras, apenas ar escrito, encontraram cobiço na medula de uma planta aquática" (VALLEJO, 2019, p. 46). Essa planta aquática é o papiro, que cresce nas orilhas do Nilo e era comercializado para o mundo lá fora desde a cidade fenícia de Biblos, no atual Líbano - daí as palavras Bíblia e biblioteca. Desta forma, a biblioteca de Alexandria se converteu no centro cultural do mundo, pelo que por muitos é considerada ninho da globalização (VALLEJO, 2019). Sofreu três incêndios, um deles por fundamentalismo religioso islâmico, que a historiadora no filme ressalta, uma vez mais destacando ao conflito Oriente-Ocidente.

O outro lugar lembrado no filme pela historiadora nos seus relatos para sua atenta filhinha é o Canal de Suez. Suez é uma cidade no Egito, capital da província com o mesmo nome, cuja riqueza é o petróleo e o canal que liga o Mediterrâneo ao Mar Vermelho, abrindo o Ocidente para o Oriente e vice-versa pela rota marítima mais curta. É um canal artificial que começou a ser construído em 1859 sob iniciativa francesa e com mão de obra egípcia - se estima cerca de um milhão e meio de pessoas trabalharam durante 10 anos, delas aproximadamente 120 mil morreram, 
principalmente de cólera (FERRER e MATTOS, 2006). De Oliveira lembra no filme na visita que a historiadora e sua filhinha fazem ao hotel onde se celebrou a cerimonia de inauguração do canal, grandiosamente representada num enorme quadro colgado de suas paredes - quando Vasco da Gama tinha que navegar ao longo de toda a costa africana para chegar à Índia.

A abertura do canal para as grandes navegações das rotas comerciais em direção à Índia e outras partes da Ásia supôs uma poupança de sete mil quilômetros, encurtando em muito o tempo levado nas viagens marítimas rodeando toda a costa africana. Nos termos de Harvey (2004), podemos apresentar o Canal como uma grande reestruturação geográfica do capitalismo, se bem incipiente, mas já capitalismo do início da Revolução Industrial, como evidenciam as disputas entre Inglaterra e França pelo seu domínio, que levaram à Convenção de Constantinopla de 1888 (o mesmo ano da abolição da escravidão no Brasil) a estabelecer o uso livre da passagem do Canal, desmilitarizando-o e proibindo os confrontos bélicos no seu espaço, inclusive fechando o canal em época de guerras - coisa que nunca foi cumprida pelas grandes potências europeias, sendo o Canal palco de vários conflitos bélicos (FERRER e MATTOS, 2006). Trazemos à memória estes fatos históricos para explicitar o canal como exemplo claro de que na globalização "a territorialização e reterritorialização do capitalismo é um processo incessante" (HARVEY, 2004, p. 85). Ainda, o grande impacto no comércio mundial da reterritorialização que supus a abertura do canal de Suez ficou muito evidente nos acontecimentos da última semana de março de 2021, quando um navio cargueiro de enormes dimensões encalhou no canal parando o trânsito marítimo durante vários dias, o que significou uma perda multimilionária para o comércio mundial - o canal é a principal via de comércio entre Europa e Ásia e palco dos $13 \%$ do transporte marítimo de mercadorias, que continuam sendo transportadas na sua grande maioria (entre um $70 \%$ e $80 \%$ ) em navios cargueiros (GONZALEZ, 2021).

No filme, uma vez que atravessa o canal de Suez, aberto pelas mãos do homem entre as terras desérticas da península do Sinai, o cruzeiro abandona o Mediterrâneo e se adentra no Mar Vermelho, que banha as costas africanas do Egito, Sudão, Etiópia e Somália, pelo lado africano, e pelo lado asiático, as costas da Arábia Saudita e lêmen. Neste último país é onde o cruzeiro faz sua última e trágica parada, saindo do Mar Vermelho, no porto de Áden (lêmen), arroupado pelo golfo que leva o mesmo nome, às margens do mar Arábico e nas costas asiáticas caminho da Índia. Por toda esta região marítima há um intenso fluxo de capital que transportam os petroleiros desde as costas do oceano Índico em direção a Europa, atravessando o estreito de Babelmândebe (no golfo de Áden), para se adentrar no Mar Vermelho e depois atravessar o Canal de Suez para chegar ao Mar Mediterrâneo.

Por que De Oliveira escolheu Áden como último lugar para o trágico destino que levou o cruzeiro e o filme ao seu fim? Lembremos com Contreras (2020) que foi em Áden onde Al Qaeda perpetrou seu primeiro ataque terrorista, em 1992 e, desde então, esta cidade portuária se converteu em palco de sucessivos atentados terroristas. A cidade portuária foi outro lugar simbólico escolhido por Manoel de Oliveira, tão simbólico quanto geopoliticamente estratégico para terroristas e barcos piratas que assaltam nas águas entre Somália e o Golfo de Áden, um dos grandes focos da pirataria marítima. No filme, justo em Áden o barco sofre um atentado explodindo com a historiadora e sua filha dentro, as únicas que não conseguem fugir a tempo. É a ameaça muçulmana assim sentida por um Ocidente que erige sua supremacia sobre o mundo com seus valores cristãos, como desde o início do filme 
o diretor evidencia quando a historiadora, ao sair do porto de Lisboa, conta para sua filha sobre a missão bélica contra o norte da África que empreendeu o rei Sebastião de Portugal com o intuito de cristianizá-lo.

Esse é o final do filme, simbolizando o final do Ocidente? O diretor, português, reservou o privilégio de atribuir à historiadora, portuguesa, que conta a história dos lugares visitados - a história contada do Filme Falado - o papel de representar a memória histórica que guarda o passado; e sua filha, que sempre pergunta sobre esse passado, o futuro. Morrem a história e o futuro de um mundo conduzido ao abismo frente ao assombro aterrado de seu capitão norte-americano. A história contada do "Filme falado" termina cumprindo a sentencia do pescador de Marselha ao começo da viagem: "Ocidente no abismo, e com ele todos os lugares por onde espalhou a sua civilização".

Harvey (2004) fala sobre os primeiros vestígios da globalização a partir da internacionalização das trocas comerciais no Mediterrâneo. É também possível observar um paralelo entre o cruzeiro conduzido por um capitão americano e o mundo às ordens do imperialismo ianque; ele ainda dialogando com o outro bloco da Tríade que lidera a globalização: a Comunidade Europeia, representada, nos jantares do cruzeiro com o capitão americano, por três mulheres: uma empresária francesa, uma atriz italiana e uma cantora grega.

Esses jantares no cruzeiro, durante os quais curiosamente cada um deles fala a sua língua e todos conseguem compreender o que está sendo dito, evidenciam a globalização através do compartilhamento da pluralidade de línguas, mas com preferências. Pois, quando a professora de história, portuguesa, é convidada pelo capitão a se unir numa das jantas, o idioma passa a ser o inglês, em razão das outras mulheres não terem domínio da língua portuguesa. $O$ diretor parece querer chamar a atenção sobre a falta de protagonismo de Portugal no cenário mundial e, então, deixa espaço para que a cantora grega questione o universalismo da língua inglesa quando, se a civilização ocidental surge no Mediterrâneo sob o Império Grego, porque não é o grego a língua universal? Mas universais são, reflete depois, as palavras com raiz grega como democracia, política, economia, hegemonia, paradigma, autonomia, ética, bibliografia, biblioteca, quilômetro, telefone, etc. De raiz grega são também as palavras método, epistemologia, utopia...inclusive pandemia!

As raízes judeu-cristãs também estão muito presentes no filme, com frequentes relatos da Bíblia. O judeu-cristianismo também penetrou fortemente através do Mediterrâneo, como vimos com o Império Bizantino, se constituindo numa cultura marcante do Ocidente - até o ponto de, na globalização, o fundamentalismo evangélico chegar a ter um peso político e econômico no Ocidente, conforme preconizado por Weber na sua ética protestante do capitalismo. Palavra muito bíblica também é o título do próximo filme a dialogar.

\section{BABEL (2007), O MUNDO CONFUSO E CONFUSAMENTE PERCEBIDO DE MILTON SANTOS (2000)}

Saindo do local (Mediterrâneo) para o global, e continuando com a linguagem bíblica, podemos estabelecer diálogo das ideias de Milton Santos (2000) com o filme "Babel", do diretor mexicano Alejandro Gonzáles Iñárruti (2007). Babel, a torre bíblica de povos de diferentes línguas que não conseguiam se entender, significa confusão e, para Santos, vivemos num mundo confuso e confusamente percebido, onde a globalização apresenta como fábula o que na realidade é perversidade, ambas caras de uma mesma moeda presentes no filme do mesmo nome. 
Babel trata sobre quatro famílias de quatro países diferentes do mundo: Estados Unidos, Japão, Marrocos e México, cujo elo é a arma de um caçador japonês, que a presenteou a um campesino marroquino que, por sua vez, vendeu para um pastor vizinho e este deixou nas mãos de seus filhos para proteger as ovelhas dos chacais. Para os filhos, ainda crianças, o rifle é quase que um brinquedo desafiante, e na tentativa de dominá-lo, atiram em um ônibus de turistas na rota de caminho ao deserto do Saara, ferindo uma turista norte-americana que estava em uma viagem de férias com o marido, deixando os dois filhos com a babá mexicana.

O incidente vai ser divulgado como ato terrorista pela imprensa norteamericana, e aí podemos ver o mundo perverso apresentado como fábula - essa fábula criada pelo Ocidente de que o mal está, depois da Guerra Fria, que culpava os países comunistas, no Oriente, e que os árabes são terroristas. Para o governo marroquino, preocupado em proteger o grande fluxo turístico, o incidente não deixa de ser uma mera tentativa de roubo.

Assim, o incidente provocado pela arma aparece nas telas da televisão do mundo todo quase no mesmo instante que os fatos estão acontecendo. Dessa forma, evidencia as conexões do mundo globalizado mediante a tecnologia, encurtando as distâncias e acelerando o tempo de comunicação, mas também manipulando a informação, como nos alertam Santos (2000) e Harvey (2004). Podemos dizer que o rifle e a televisão representam a unicidade da técnica da que nos fala Santos (2000).

Babel mostra também a "globalização perversa" quando observada a necessidade do trabalho infantil para a sobrevivência de muitas famílias, já que os meninos marroquinos no filme trabalhavam pastoreando ovelhas para ajudar na renda da família. Marrocos representa para o mundo lá fora um país subdesenvolvido, atrasado e sujo, como observamos na desconfiança da turista estadunidense na hora de ser servida num bar popular marroquino. Mas, por que 0 marido, num momento de crise matrimonial por conta da perda de um filho, decide levar a sua mulher numa viagem se expondo a tanta "desventura"? Marrocos também é um país exótico para o turismo pela sua geografia diversificada de belezas naturais e cultura tradicional, de tal forma que o turismo é uma das principais fontes de ingressos, graças também a uma estabilidade política sem ameaça terrorista recente, que faz dele um dos lugares árabes mais seguros para o ocidental transitar.

Para o governo marroquino, no seu território, o terrorismo está controlado e a sua preocupação é com a malandragem para com o turista, como mostra o fato de que os marroquinos são proibidos de se misturar de forma espontânea com os turistas. Mas, este estereótipo do próprio marroquino com seu povo, de que sempre queira se aproveitar do turista, é desconstruído no filme quando o guia marroquino, principal ajuda e interlocutor do casal estadunidense, rejeita o dinheiro que em agradecimento queria Ihe dar o marido da atingida pelo rifle. Na pequena aldeia que hospeda ao casal norte-americano, o diretor mostra a solidariedade de um povo isolado pela áspera geografia até de seu próprio governo, e que vive às margens do capitalismo ocidental. Interessante observar aqui como os espaços micros do local guardam certa autonomia com respeito ao território nacional - como as comunidades tradicionais rurais, quilombos e aldeias indígenas do Brasil - girando em torno da sua própria órbita, com seus costumes libertadores - como o uso do haxixe que a velinha dá à ferida pelo rifle para aliviar as suas dores, quebrando nesse momento a desconfiança dela. 
Também a globalização perversa obriga, no outro canto do mundo, à babá mexicana a emigrar, se distanciando da sua família para cuidar a dos outros nos Estados Unidos, ainda clandestinamente, porque para o latino-americano pobre as fronteiras não estão abertas - essa é outra fábula da globalização. Pois, que representa o México para seu país vizinho, os Estados Unidos? "Mamãe diz que é muito perigoso" comentará à babá mexicana para o filho do casal norte-americano quando chegam na cidade da família da babá para a festa do casamento do filho. $O$ sobrinho da babá responderá com ironia que sim, que México é perigoso porque "está cheio de mexicanos". "Este estigma de periculosidade, que frequentemente destinamos ao desconhecido e ao "Terceiro Mundo", tem sido muito potencializado por Trump, que considera os mexicanos e emigrantes em geral, como um perigo para a economia norte-americana; e como considerou terroristas os manifestantes contra o assassinato de George Floyd.

Enquanto isto, os países latinos próximos se afundam na miséria e na violência ao mesmo tempo em que sonham com alcançar a globalização apresentada como fábula. Por isso, a fronteira entre Estados Unidos e México tem sido cenário de muitos dramas de migrantes latinos querendo alcançar a fábula da globalização do progresso e do bem estar capitalista, fato que em Babel vai ser o ponto de partida de outra tragédia que se desenvolve em terrenos também áridos e inóspitos como em Marrocos, mas no outro lado do mundo. A babá mexicana, que leva os filhos de seu patrão norte-americano para o casamento de seu filho na cidade natal, no seu retorno é barrada na fronteira por levar crianças estadunidenses que não são filhos dela e sem documentos, o que vai desencadear uma série de agonias que termina na deportação pela sua situação ilegal, depois de toda uma vida construída com seu suor no paraíso sonhado - a "fabulo-sa" América que nunca a considerou como cidadã.

À vista disso, vale lembrar que a construção de um muro entre os Estado Unidos e México formou parte da campanha eleitoral do governo de Trump, com o objetivo de evitar a imigração ilegal através da fronteira sul dos Estados Unidos, mostrando assim intolerância e falta de alteridade para com um país que, historicamente, tem formado parte de um dos grandes blocos econômicos da Tríade: o Tratado do Atlântico Norte ou NAFTA, entre Canadá, Estados Unidos e México.

Em Babel, Iñárritu apresenta dramas sociais muito atuais, retratando as formas da globalização que impera no mundo e as conexões existentes entre a globalização como fábula e a como perversidade. Assim, no filme, o México e Marrocos representam os territórios de famílias que vivem o drama cotidiano pela sobrevivência, mas no fabuloso mundo da globalização as famílias também vivem seus dramas - dramas da incomunicabilidade e solidão da mulher norte-americana e da adolescente japonesa, que se sentem carentes num mundo rodeado da riqueza material.

O que representa para o mundo lá fora o Japão, o outro país que forma parte do quebra-cabeça de Babel? Esse país tão distante do mundo ocidental e de cultura tão diferente, que nos anos de 1970 desbancou a produção fordista com o modelo toyotista de produção, baseado no trabalho em equipe e em "cooperar para competir", segundo Harvey (2006); o país da Toyota, Yamaha, Nintendo, Honda, Sony, Canon, representa o mundo do perfeccionismo educacional e da disciplina para o trabalho que resultou na alta tecnologia digital através da qual a turma de jovens surdas em Babel se comunica. As imagens de Tóquio apresentadas em Babel, com ruas invadidas de telas propagandísticas de um mundo fabuloso, lembram a ficção futurista retratado no famoso filme de Ridle Scott, Blade Runner. 
Os jovens japoneses, nem sequer as próprias amigas, sentem empatia com a jovem surda, filha do caçador que presenteou o rifle à família marroquina, que só vai encontrar o abraço fraterno no policial que investiga o caso $\mathrm{e}$, finalmente, no encontro com o pai na varanda exposta nuamente à cidade global. Mas também faltou empatia nos turistas ocidentais, que não queriam esperar na aldeia marroquina a recuperação da companheira de viagem atingida pela bala. A babá mexicana também não encontrou com quem deixar os filhos dos patrões quando viajou para o casamento de seu filho na sua terra natal; também não encontrou apoio de seus patrões quando voltaram, tendo que retornar, deportada, para sua família no México.

Frente à carência afetiva num mundo onde todos somos alienados de forma global, o diretor coloca a esperança na família, nas quatro famílias do filme, alocadas em quatro territórios, quatro culturas diferentes. E nós, lembramos a família planetária e a solidariedade para com o outro num outro mundo possível, regido por uma outra globalização, como aponta Milton Santos (2000).

\section{ENTRE A GLOBALIZAÇÃO PERVERSA EM "ENSAIO SOBRE A CEGUEIRA" E POR UMA OUTRA GLOBALIZAÇÃO NO HOTEL CAMBRIGDE}

Muito tem já se escrito e analisado, com artigos, dissertações e teses, tanto sobre a obra mestre do escritor português Prêmio Nobel José Saramago, "Ensaio sobre a Cegueira", levada ao cinema pelo diretor brasileiro Fernando Meirelles, quanto sobre o filme/documentário de Eliane Caffé, "Era o hotel Cambridge". Aqui nos referiremos a essas duas grandes obras sob a ótica da globalização de Harvey e Santos.

Com a interpretação desta obra levada ao cinema, partimos do pressuposto de que interpretar um filme não é o mesmo que interpretar uma obra literária; e é um grande desafio levar ao cinema uma obra literária que dificilmente pode superar seu original, mais ainda quando escrita por um Nobel - a obra costuma estar mais bem representada na literatura. Mas Saramago, que se emocionou na estreia do filme, ficou muito feliz da interpretação cinematográfica que Meirelles fez de sua grande obra (ROLIM, 2008), sobre a que tratamos através do cinema - um meio mais acessível para uma geração criada com o mundo visual se aproximar a uma trama tão complexa. "Ensaio sobre a Cegueira" trata de uma epidemia de uma "cegueira branca", que atingiu toda a população de uma cidade moderna onde apenas uma mulher ficou imune. Os espaços apresentados são as ruas transitadas da cidade global e um manicômio lúgubre abandonado onde os infectados são recluídos, à semelhança dos hospitais de campanha dos infectados do COVID-19, também nas cidades globais. No desenrolar do filme centenas de pessoas infectadas pela epidemia são jogadas nesse manicômio numa situação precária e onde os conflitos são acirrados, manifestando-se assim em menor escala o lado perverso da humanidade.

É possível refletir que não só lá, mas também do lado de fora o governo está sumido num caos, sem se comunicar com os infectados em nenhum momento para dialogar - como ficou o Ministério da Saúde no Brasil para enfrentar a pandemia do coronavírus. Em ambos os casos se evidenciaram o despreparo para situações extremas e, sobretudo, o desprezo pela vida. A cidade atingida pela epidemia ficou 
totalmente devastada e seus habitantes à mercê da própria sorte, num cenário de apocalipse.

O território palco da cegueira branca de Saramago é uma cidade global, que poderia ser qualquer uma das cidades epicentros da pandemia do coronavírus. centros industrias, financeiros e/ou do turismo como Wuhan, Milão, Madri, Munique, Nova lorque e São Paulo. A maneira como a cegueira branca se dissemina no filme é semelhante à forma como o coronavírus se alastrou por quase todo o Planeta Terra, no início de 2020. Na trama em questão, os infectados pela cegueira branca, confinados pelo governo no manicômio, estavam sem o auxílio de profissionais da saúde e sob a vigilância do exército, que matava qualquer pessoa que tentasse sair do confinamento. Por conta, principalmente, do encurtamento das distâncias entre os lugares e das aglomerações nos centros urbanos, somados à falta de políticas, ações e investimentos de alguns países, a exemplo do Brasil, na saúde pública e nos setores de pesquisas científicas, o combate imediato de doenças contagiosas e mortais nestas cidades globais foge do controle estatal.

O "Ensaio sobre a Cegueira" nos convida a refletir sobre a Globalização Perversa descrita por Milton Santos (2000), individualista e cega, que reina nas cidades globais, onde muitas pessoas são cegadas pela mídia e pelo consumo e/ou cegas porque veem, mas se negam a enxergar a realidade. Mas também nas cidades globais encontramos espaços de solidariedade ondem lutam por outro mundo possível, inclusive no Brasil. Este é o caso de uma outra globalização no Hotel Cambridge.

Em "Era o Hotel Cambridge", a diretora Eliane Caffé (2016), que conhecemos no seu filme "Narradores de Javé", mistura realidade com ficção para trazer à tona a problemática do direito à cidade e o direito à moradia dos sem teto em cidades globais como São Paulo, que já acolhe também refugiados políticos do Oriente Médio e do continente africano nessa multiculturalidade intensificada pela globalização.

O hotel Cambridge é um enorme prédio construído no final da década de 1950 no centro histórico de São Paulo que oferecia hospedagem de luxo - por ele passaram famosos do mundo inteiro - até sua falência em 2002. Abandonado e com dívidas de Imposto sobre a Propriedade Predial e Territorial Urbana (IPTU), foi desapropriado pela prefeitura de São Paulo e transformado em moradia popular após a pressão da ocupação do Movimento dos Sem Teto do Centro (MSTC) (DE MIRANDA, 2017).

Os protagonistas do filme são os próprios protagonistas da ocupação, representando-se a eles mesmos: brasileiros e não brasileiros - nordestinos, congolense, palestino, sírio, colombiano... - todos igualmente "refugiados de seus direitos a uma vida digna", como se posiciona um dos ocupantes frente a comentários xenófobos. Carmen Silva, baiana, de garra, mãe de oito filhos, no filme representa a ela mesma: "retirante que dormiu nas ruas de São Paulo no início dos anos 1990 e que se tornou líder do MSTC" (ZAIDAN, RAQUEL, 2019, p.1).

A globalização perversa pode ser notada a partir de várias cenas, sobretudo nas que os refugiados aparecem explicando por que tiveram que sair de seu país natal por conta de conflitos bélicos. Todavia, ao chegarem ao Brasil, se deparam com outra dura realidade, como a falta de um lar e de oportunidades de emprego, igual a outros brasileiros, fundamentalmente nordestinos, que também se viram forçados a migrar. Os refugiados globais do Hotel Cambridge vivem seu mundo privado em cada canto do prédio, onde conseguiram de forma improvisada construir seu lar - inclusive o palestino colocou nele uma quitanda para venda interna. 
O prédio tem também espaços comunitários, onde os moradores celebram reuniões para as reflexões e tomada de decisões coletiva. Tanto os lares individuais quanto os lugares coletivos são espaços de socialização multicultural e intercâmbio de costumes alimentares, músicas e ideias políticas entre as diferentes nacionalidades ali presentes. Assim, a nordestina repara sobre o significado dos sinais com as mãos em diferentes culturas, o congolês comenta quanto variada é a alimentação no país dele, frente ao arroz e feijão da comida brasileira; o palestino surpreende com a poesia árabe e o colombiano fala para o sírio que sua cantora favorita não é a internacionalmente conhecida na indústria cultural Shakira, mas Lucia Pulido, cantora popular que inclusive canta uma música desde México para ele pela internet na lanhouse, deixando todos ali presentes, admirados. Nesses pequenos detalhes de grande sensibilidade, Caffé (2016) nos mostra que todo povo tem cultura e que a cultura que circula fora do circuito comercial também pode encantar o povo até de outras culturas.

A lanhouse é outro espaço de socialização e comunicação importante para os moradores do Hotel Cambridge: é a janela para o mundo lá fora através da nova "unicidade da técnica" da que fala Santos (2000). Na lanhouse tanto o palestino quanto o congolês e o colombiano vivem mais de perto o drama sofrido pelas suas famílias que deixaram nos seus países. Mas também vivem o dilema de ter que se adaptar ao 'lugar onde emigraram e, assim, quando o irmão reclama a presença do congolês para cuidar da família que deixou, responde que já não é o mesmo, que agora é cidadão de São Paulo.

A unicidade da técnica no Hotel Cambridge, o celular, é usado pela própria diretora para mostrar outra perversidade da globalização, numa das cenas mais marcantes do filme, durante uma dinâmica de grupo envolvendo representações que lembram o Teatro Experimental do Negro, de Abdias Nascimento, e o Teatro do oprimido, de Augusto Boal. Na cena, o congolês exibe seu instrumento de comunicação com o mundo que deixou atrás ao mesmo tempo em que mostra que nesse mundo, no seu país, a República popular do Congo, se encontram as maiores reservas de coltan, mistura de vários minerais usados na alta tecnologia, como a fabricação de celulares e computadores portáteis. A disputa internacional pelo controle das muito escassas terras de coltan tem gerado graves conflitos bélicos dentro do país, forçando a emigração.

Ao longo do filme, aparecem falas marcantes, como quando o refugiado congolês afirma que o mal do século XXI são as pessoas saindo de suas pátrias, não porque querem, mas para fugir das guerras - "a guerra é o ar que os Estados Unidos e a Europa respiram" - para fortificar as suas economias. O refugiado palestino diz, emocionado, "sempre vivi em um país ocupado, agora pela primeira vez estou ocupando algo". São falas sofridas sobre a desigualdade, as guerras e a pobreza da globalização perversa, mas também deixam deslumbrar a utopia de um dia ter seus direitos assegurados verdadeiramente, sonhando assim com uma nova globalização. Na conquista desse sonho, a rua constitui o espaço de luta para os moradores do Hotel Cambridge, porque "a nossa ordem vai ser a desordem".

Após várias manifestações na rua e atos de resistência amparados por advogados, a utopia foi alcançada quando os ocupantes conseguiram a posse do hotel. Em 2010, a prefeitura de São Paulo desapropriou o prédio e em 2012, foi declarado moradia popular. Ainda em 2015, o MSTC ganhou um edital com financiamento para a transformação do prédio em 121 unidades habitacionais (DE MIRANDA, 2017). São os espaços de esperança (HARVEY, 2004) de outra globalização (SANTOS, 2000): grande prédio construído para ser um hotel de luxo no contexto da 
especulação imobiliária das metrópoles globalizadas, que vira moradias populares para os sem teto, sem país, sem cidadania. São as novas condições técnicas permitindo "a ampliação do conhecimento do planeta, dos objetos que o forma, das sociedades que o habitam e dos homens em sua realidade intrínseca" (SANTOS, 2000, p. 39); e, como diria Harvey (2004, p. 258), "a tarefa é montar um utopismo espaço temporal - um utopismo dialético".

\section{CONSIDERAÇÕES FINAIS}

No mundo global do 2020, a pandemia do coronavírus deslocou as miras do Ocidente para a China Oriental, que teve um papel fundamental no florescimento das grandes civilizações egípcia, mesopotâmica, persa, indiana, e todas as civilizações do Mediterrâneo, deixando sua marca também na fundação do mundo moderno; tudo isso com o comércio através da milenar Rota da Seda, que conectava Xiam com Antioquia. A rota milenar decaiu junto com o Império Bizantino e também por conta de ter veiculado a maior pandemia da história da humanidade: a Peste Negra, que devastou o território da Eurásia, causando entre 70 e 200 milhões de mortos, no século XIV (KOTZ, 2018).

"Um Filme Falado" nos trasladou à região geopoliticamente estratégica do Mediterrâneo, cuja viagem nos serviu para nos adentrar na geografia das cidades portuárias mais destacadas de sua costa por serem lugares entendidos como construções históricas de longas datas e constantes transformações ao longo do tempo. No cruzeiro simbolizando o mundo capitaneado pelos Estados Unidos em parceria com a União Europeia, deslumbramos a guerra pelo petróleo dos países muçulmanos e a ameaça do terrorismo islâmico que desde finais do século XX tem aterrorizado o mundo ocidental. Mas com a nova pandemia do COVID-19, originária também na China, Ocidente parece ter esquecido seu medo do terrorismo, ao focar seu olhar neste país de grande potencial para liderar os novos processos de globalização.

A China se erigiu no cenário mundial como uma das fortes lideranças nos processos de globalização desde que começou em 2013 a traçar uma nova Rota da Seda, também denominada Belt and Road Initiative ou BRI, não precisamente para comercializar seda, mas alta tecnologia; e não precisando abrir canais como o de Suez, mas pontes, estradas, ferrovias, aeroportos e portos desde a Ásia, passando por Europa e parte de África até chegar às Américas. Dez países latino-americanos já assinaram a adesão a este projeto geoestratégico (Brasil ainda avaliando) (KOTZ, 2018). Podemos considerar que a rota vai chegar inclusive à ilha de Itaparica na Bahia, onde o governo do estado planeja a contratação de empresas chinesas para a construção da ponte (SEPLAN, 2019) para escoar a produção desde Salvador por todo o Recôncavo, até chegar ao sul da Bahia e neste sentido, poder continuar para Espírito Santo e Rio de Janeiro.

A nova Rota da Seda foi planejada para ser concluída em 2049, em comemoração aos 100 anos da Revolução de Mao Tse Tung. Mas o coronavírus parece ter se adiantado, traçando de forma veloz sua rota, a Rota do COVID-19 pelos aeroportos internacionais e nos epicentros das grandes cidades financeiras e turísticas, desde Wuhan até Nova York, passando pela região de Kerala na Índia, Teerã, Milão, Madri, Barcelona Paris, Newcastle, Munique, São Paulo e Rio de Janeiro, dentre outras muitas cidades. Estas capitais globais de grande fluxo comercial, financeiro e/ou turístico têm sido os epicentros de uma pandemia que 
está desvelando de forma escancarada os efeitos perversos de uma globalização excludente e devastadora com o meio ambiente.

Para Harvey (2020), o COVID-19 é, como Babel, a vingança da natureza por quarenta anos de maus-tratos e abusos de ações devastadoras como a exploração das riquezas naturais para favorecer o consumo que alimenta o grande capital, um consumo que tem alienado grande parte da população, com e sem poder aquisitivo, ao poder das marcas e da tecnologia digital, massificada principalmente com os celulares, que aqui consideramos a unicidade da técnica da que fala Milton Santos (2000).

A pandemia do coronavírus, que surgiu assim de repente, como a cegueira branca de Saramago, veio para desvendar o nível de perversidade da globalização contemporânea, que vai se concentrar nos lugares mais globalizados do planeta, onde a densidade populacional e a mobilidade interurbana são grandes e o fluxo do capital financeiro intenso - cidades conectadas em rede e globais como Nova Iorque, São Paulo, Milão e Madri têm sido os epicentros mundiais da pandemia do coronavírus; cidades onde a maioria depende de longos trajetos em transporte público para ir trabalhar; de grandes supermercados e shoppings para ir comprar; de academias para se exercitar; de aeroportos com grande numero de voos internacionais... Todos estes lugares têm se tornado uma ameaça para a saúde na mencionada pandemia, além de, como consequência, ter recebido um grande impacto negativo em suas economias, principalmente as companhias aéreas - a diferença das mercadorias, que continuam circulando maioritariamente em barcos, arribando portos, o avião tem sido o principal meio de transmissão do coronavírus, que mundialmente se espalhou pelos aeroportos internacionais.

Mas as cidades globais também são espaços de resistência, principalmente para os excluídos, os sem teto, "sem lugares", que valorizam ao mesmo tempo a experiência da escassez e a experiência da convivência e da solidariedade, como nos fala Harvey (2014) em suas "Cidades rebeldes". É o que temos visto no Hotel Cambridge, e nos perguntamos como estarão enfrentando e como lhes estará afetando a pandemia do COVID-19 a seus ocupantes, e a tantos outros sem teto que ainda estão lutando nas ocupações.

A socialidade urbana e mundana da que fala Santos (2000, p.67) que "pode escapar aos seus intérpretes, nas faculdades; ou aos seus vigias, nas delegacias de polícia; mas não aos atores ativos do drama, sobretudo, quando para prosseguir vivendo, são obrigados a lutar todos os dias", como vai escapar desta pandemia, que colocou em xeque a "normalidade" estabelecida para abafar o caos com a ordem do dinheiro? Como vamos escapar desta Babel que deixou o mundo ainda mais confuso e confusamente percebido, conectado exaustivamente pelas redes sociais dos fakes news, ao mesmo tempo que confinado no espaço privado, que para muitos deve ser um cubículo, enquanto que uns poucos podem fugir navegando na sua própria embarcação para o Caribe?

Continuaremos apostando pela força do local num mundo cada vez mais global, e onde o espaço urbano seja o palco de importantes ações e revoltas políticas, como foi palco das manifestações de protesta e revolta contra a violência colonial por vários pontos do planeta a raiz da morte de George Floyd; onde "reivindicar o direito de todos a viver em uma casa e um ambiente decente pode ser visto como o primeiro passo de um movimento revolucionário mais abrangente" (HARVEY, 2014, p. 245), que abranja o planeta Terra como lar onde todos cabeamos e todos cuidemos. Grande utopia nesta distopia da pandemia, mas 
vamos deixar espaços para a esperança e continuar lutando por uma outra globalização.

\section{REFERÊNCIAS BIBLIOGRÁFICAS}

AGNEZ, Luciane Fassarella. Consumo da informação na sociedade contemporânea In: Congresso Brasileiro de Ciências da Comunicação, 32., 2009, Curitiba. Anais. Curitiba: Sociedade Brasileira de Estudos Interdisciplinares da Comunicação. Disponível <http://www.intercom.org.br/papers/nacionais/2009/resumos/R4-1182-1.pdf>.

em: Acesso em: 20 de jun. 2021.

ALVES, Eliane Serrão Alves. Biblioteca Alexandrina. Revista Digital de Biblioteconomia e Ciência da Informação, Campinas, v. 1, n. 2, p.71-91, jan./jun. 2004. Disponível em: <https://periodicos.sbu.unicamp.br/ojs/index.php/rdbci/article/view/2081/2211>.

Acesso em: 06 maio 2020.

BABEL. Direção: Alejandro Gonzalez Iñárritu. Produção: Alejandro González Iñárritu, Jon Kilik e Steve Golin. Estados Unidos/México: Paramount Pictures, 2006 (143 min.). 1 DVD.

BERNARDET, Jean Claude. O Que é Cinema. 2017. Disponível em: $<$ https://www.academia.edu/3746096/O Que \%C3\%A9 Cinema Jean Claude Ber nadet>. Acesso em: 21 jun. 2021

CONTRERAS, José Ignacio. 10 años de la caza de Osama bin Laden (I): Los inicios.

$<$ https://www.descifrandolaguerra.es/10-anos-de-la-caza-de-osama-bin-laden-i-losinicios >. Acesso em: 24 dez. 2021.

DE MIRANDA, Felipe Villela. Como os sem-teto se tornaram planejadores urbanos em São Paulo? XVII Encontro Nacional da Associação Nacional de Pós-Graduação e Pesquisa em Planejamento Urbano e Regional, 2017. Anais. Disponível em: $<$ http://anais.anpur.org.br/index.php/anaisenanpur/article/view/1817>. Acesso em: 20 mar. 2021.

ENSAIO sobre a cegueira. Direção: Fernando Meirelles. Produção: Andrea Barata Ribeiro, Niy Fichman e Sonoko Sakai. Estados Unidos: Distribuição 20th Century Fox/ Brasil: Miramax Film, 2008 (122 min.). 1 DVD.

ERA o Hotel Cambridge, Brasil. Direção: Eliane Caffé. Produção: rui Pires. Brasil: Aurora Filmes, 2016 (100 min.). 1DVD.

FERRER, Francisca Carla; MATTOS, Júlia Silveira. A construção do canal de Suez e a formação do conflito: a força de paz brasileira na faixa de Gaza. Revista do Instituto de Ciências Humanas e da Informação, v. 19, p. 43-53, 2006. Disponível em: <http://repositorio.furg.br/bitstream/handle/1/203/65.pdf? sequence $=1>$. Acesso em: 10 maio, 2020. 
FREIRE, Paulo. Pedagogia do oprimido. Rio de Janeiro: Paz e Terra, 1987. 107 p.

FIORANTE, Karina Eugenia; FERREIRA, Lohanne Fernanda Gonçalves. Ensino de Geografia e cinema: perspectivas teóricas, metodológicas e temáticas. Revista Brasileira de Educação em Geografia, Campinas, v. 6, n. 12, p. 209-233, jul./dez., 2016. Disponível em: <http://www.revistaedugeo.com.br>. Acesso em: 24 jun. 2021.

GONZALEZ, Alicia. La crisis del canal de Suez da la puntilla al comercio mundial. El País, 28 de março 2021.

HARVEY, David. A Globalização contemporânea. In: HARVEY, David, Espaços de esperança, São Paulo: Edições Loyola, 2004. Cap. 4, p 79-103.

HARVEY, David. Cidades rebeldes: do direito à cidade à revolução urbana. São Paulo: Martins Fontes, 2014. 294 p.

HARVEY, DAVID. Política anticapitalista em tempos de coronavírus, Blog da Boi Tempo, São Paulo, 2020. Disponível em: $<$ https://blogdaboitempo.com.br/2020/03/24/david-harvey-politica-anticapitalista-emtempos-de-coronavirus/>. Acesso em: 03 abr. 2020.

KOTZ, Ricardo Lopes. A nova rota da seda: entre a tradição histórica e o projeto geoestratégico para o futuro. Dissertação - Universidade Federal de Santa Catarina, Centro Sócio-Econômico, Programa de Pós-graduação em Relações Internacionais, $\quad$ Florianópolis, 2018. Disponível em: <https://repositorio.ufsc.br/handle/123456789/193931>. Acesso em: 03 ago. 2020.

LENIN, Vladimir Illitch. O Imperialismo: etapa superior do capitalismo. Campinas, SP: FE/UNICAMP, 2011. $270 \mathrm{p}$.

OLIVEIRA JR., Wenceslau Machado de. O que seriam as geografias de cinema? Leituras Transdisciplinares de Telas e Textos, Belo Horizonte, v.1, n.2, p.27-33, 2005. Disponível em: shttp://www.periodicos.letras.ufmg.br/index.php/txt/issue/download/411/24>. Acesso em: 06 jun. 2021.

QUEIROZ FILHO, Antonio Carlos. Vila-floresta-cidade: territorio e territorialidades no espaço filmico. 2009. Tese (doutorado) - Universidade Estadual de Campinas, Instituto de Geociencias, Campinas, SP, 2009. Disponível em: <http://www.repositorio.unicamp.br/handle/REPOSIP/287429>. Acesso em: 25 jun. 2021.

ROLIM, Maria Luiza. Saramago chora com o filme de Meirelles. Expresso, Laveiras, 2008. Disponível em: <https://expresso.pt/actualidade/saramago-chora-com-filmede-meirelles=f437551>. Acesso em: 22 jun. 2021.

RUNCIMAN, Stefan. A civilização bizantina. Rio de Janeiro: Zahar, 1961. 233 p.

SANTOS, Milton. Por uma outra globalização: do pensamento único à consciência universal. Rio de Janeiro: Record, 2000. 174 p. 
Secretária do Planejamento (SEPLAN). Consorcio chinês vence leilão da Ponte Salvador-Itaparica.

$<$ http://www.seplan.ba.gov.br/2019/12/1112/Consorcio-chines-vence-leilao-da-PonteSalvador-ltaparica.html>. Acesso em: 24 jun. 2021.

SOUZA, Vanessa de Freitas. CINEMA: História, linguagem e ensino. Mosaico (Instituto de Biociências, Letras e Ciências Exatas - UNESP), São José do Rio Preto, SP, 2017. Disponível em: $<$ http://www.olhodagua.ibilce.unesp.br/index.php/revistamosaico/article/viewFile/450/ 420>. Acesso em: 22 jun. 2021.

UM FILME Falado. Direção: Manoel de Oliveira. Produção: Paulo Branco. PortugalFrancia-Italia: Mandragoa Filmes, Gemini Films, Mikado Film. France 2 Cinema, ICAM, Radiotelevisão Portuguesa, CNC, 2004 (96 min.). 1 DVD.

VALLEJO, Irene. El infinito en un junco. Madrid: Ediciones Siruela, 2019.

VENACIO, Daina Seabra. A definição de pirataria marítima e as implicações para a segurança na navegação. Revista da Escola de Guerra Naval, Rio de Janeiro, v.18, n. 2, p. 135-157, jul/dez 2012. Disponível em: $<$ https://revista.egn.mar.mil.br/index.php/revistadaegn/article/view/233/195> $>$. Acesso em: 23 jun. 2021.

ZAIDAN, Patrícia; RAQUEL, Martha. Quem é Carmen Silva, a líder dos sem-teto que a (in)Justiça quer prender, Jornalistas livres, 2019. Disponível em: https://jornalistaslivres.org/carmen-silva-a-lider-dos-sem-teto-que-a-injustica-querprender/. Acesso em: 20 mar. 2021. 